\title{
Correspondence
}

\section{Morality of surgical abortion at twenty weeks}

\author{
SIR
}

Lilford and Johnson (1) suggest that some actions have an intrinsic moral quality which is distinct both from their consequences and from the intent of their perpetrators. They argue that the repugnance which most people have to late surgical termination makes it morally worse than an otherwise identical medical termination. This sort of appeal to recognise intrinsically bad acts is frequently made. It is difficult to see what criteria are offered, apart from the emotive consequences, as evidence that surgical termination is uniquely bad. Certainly the emotional distress caused to the medical attendants and the possible brutalising effect on both them and society are morally relevant. However, these are simply consequences of the act. They require consideration in their turn, together with the effect of the termination on suffering and on the autonomy of persons.

This is not what Lilford and Johnson have in mind. They believe that the emotional and symbolic effects of an unpleasant procedure cause it to be intrinsically immoral quite apart from any moral status derived from its effects on autonomy, utility and justice. Their argument is similar to the acts and omissions doctrine which sees an intrinsic moral distinction between killing and letting die. Most philosophers now argue that the difference here is not a result of an intrinsic difference between acts of omission and commission, but rather results from differing consequences of the two acts $(2,3)$. These different consequences will include the risk of brutalising doctors required to carry out euthanasia.
Lilford and Johnson claim that most people intuitively feel that surgical abortion is more abhorrent than medical termination. I suggest that this is a consequence, not of something intrinsic to the method, but of the real fear that a fetus which can feel pain is being dismembered. Most people also find post mortem examination distasteful but few believe that it is intrinsically wrong. If post mortem examinations are ever wrong, it is because they offend surviving relatives, or brutalise the mortuary staff. The wrongness is not intrinsic to the distasteful business of dissecting dead bodies. Similarly there are no moral objections to surgical evacuation of already dead 20 -week fetuses.

The authors provide two thought experiments in which we are invited to observe moral distinctions between pairs of actions, whose consequences are apparently identical, but whose intrinsic morality is different. In both cases there are consequential differences which more plausibly explain our intuition that the actions are morally distinct. Firstly, the story by John Fowles is undoubtedly a powerful piece of writing, but our intuition that bludgeoning a man to death is worse than shooting him is, I suggest, a result of the consequence that the former causes more suffering and requires a more prolonged intent to kill. In the second example there is a significant consequential difference between planting a bomb with a time device which will probably harm many people and detonating one under direct vision which will certainly kill many people. I suggest that this is sufficient to explain the fine moral distinction we make between the two acts.

How might Lilford and Johnson test their theory? One way would be to find situations where the intrinsic immorality of surgical evacuation overrode another moral principle. I do not think that such situations exist.
Imagine that the risks of upsetting or brutalising participants were the same with medical and surgical termination. Would medical termination ever be justified if it was shown to be more dangerous to the mother? Would it be justified if the informed mother preferred surgical termination, or if it caused more suffering to the fetus? The final example shows that if medical termination caused more fetal suffering, it would also become more 'intrinsically immoral'. I conclude that 'intrinsic immorality' is no more than fear of causing the fetus suffering.

Lilford and Johnson are nevertheless correct to remind us that surgical abortion may not minimise the mother's suffering if she is likely in future to find out the details of the method. However, the authors have selectively used emotive terms to describe the types of abortion. If they reminded readers that the mode of fetal death in medical termination was usually slow asphyxiation, the relative morality of the methods would appear somewhat different.

I do not believe that Lilford and Johnson really wish to introduce a principle that surgical methods of causing death are intrinsically worse than medical. If they do they must depend ultimately on an arbitrary appeal to their own or other doctors' authority and accept the risk that other people at another time will appeal to different authorities. I fear that it is not possible to judge the morality of an act without reference to all its consequences. In practical terms, those of us who believe that late termination is sometimes morally correct need to ensure that the risk of causing suffering to the fetus is minimised. This can probably best be done by a lethal intravascular injection before emptying the uterus by either method.

References

(1) Lilford Richard J, Johnson 
Nicholas. Surgical abortion at twenty weeks: is morality determined solely by the outcome? Fournal of medical ethics 1989; 15:82-85.

(2) Rachels J. Active and passive euthanasia. New England Fournal of medicine 1975; 292:78-80.

(3) Glover J. Causing death and saving lives. Harmondsworth: Penguin, 1977: 92-116.

J G THORNTON Lecturer in Obstetrics and Gynaecology University of Wales College of Medicine Heath Park

Cardiff CF 4 4XN

\section{Response on late surgical abortion}

SIR

Thornton's repudiation of our agument seems to go something like this. We were wrong to claim that something can be morally important purely because of its symbolic effects - its effects upon our emotions. He would argue that the moral force of a symbolically unattractive action, is the result of a long-term consequence of that action (for example brutalising people). We disagree. The argument that actions are judged in terms of their outcomes, is utiltarian. Thornton wants to say that utilitarian arguments must also take into account indirect and very longterm effects, including those resulting from adverse effects on human psychology. Our argument is based on emotional considerations. In other words, we are concerned to include the symbolism of certain acts in ethical debate. We deliberately avoided using the words utilitarian and deontological, because if utilitarian considerations include emotional and symbolic effects and if they also include the very longterm outcomes of actions, then the distinction between the two becomes difficult to define. In this sense, we share ground with Thornton - we are happy to see the adverse symbolic and emotional effects of manual destruction of the fetus as an effect of the act of 'surgical abortion'. We think the symbolism of acts is important. That is why we think that sniping is a more serious violation than bombardment by cannon, all other things being equal, because of the emotional connotations of seeing the person who is about to be destroyed.
There is another serious point in which Thornton misunderstands us. We do not argue that late surgical termination is morally wrong because of the violation of human sensitivities involved. We merely said that this violation of human sensitivities has moral force and should be taken into the equation. Thus we do not say that sniping is never justified (although it happens to be our view that this is only justified by the most extreme provocation). Similarly, to take up Thornton's argument about post mortem examinations; we do think that the violation in post mortem is morally relevant, purely for its symbolic (emotional effects). This does not mean that post mortem is wrong. In this case other considerations (finding the murderer, auditing medical diagnosis) have greater force. Similarly, it is morally correct to wring the neck of a mortally injured bird, because this again is the lesser of two evils, if the bird is suffering and no other means are available to expedite its demise. We would not, however, wring the neck of the Christmas goose. Our argument is that in the case of late termination of pregnancy there is no clear evidence that surgical termination is psychologically or medically preferable, and that human sensitivities arising from the physical violation involved can legitimately be taken into account in decision-making.

\section{Moral force}

Finally, we do not believe that doctors are brutalised by carrying out physical destructive procedures, such as post mortems and terminations of pregnancy - if anything the effects are the opposite to this, provided that the procedures are morally justified. We think that the emotional impact of actions per se are morally important, quite apart from any knock-on effect of symbolically undesirable procedures. We think these factors have moral force, but this moral force is not always overriding.

Lethal intravascular injection srikes us as a sensible idea and we would not oppose a doctor doing late surgical termination if he/she believed this was safer or psychologically preferable to medical methods.

RICHARD J LILFORD MRCP, PhD, MRCOG Professor of Obstetrics and Gynaecology The University of Leeds St Fames's University Hospital Leeds LS9 7TF

\section{Ethical obligation arising from routine screening}

SIR

I wonder whether it is appropriate to ask for your help and that of your readers with a practical problem which a literature search has not cast any light on?

As a district we are evaluating our cervical smear service, and one of our consultant pathologists recently raised the problem of women who have attended for initial screening, but then fail to re-present to their GP when requested to do so by him or her as the laboratory has informed the doctor of an abnormality, because they have moved house but not left a full forwarding address.

Cambridgeshire FPC will check and forward the result to the new GP if someone has re-registered in the county. It becomes problematical when people move further afield, and there are a number of situations which we have already experienced which cause us concern.

The result can be included in the brown envelope if its arrival has been the stimulus which has indicated that the woman is effectively no longer a patient of that practice, but may then wait unheeded for months at the NHS Central Register before the woman reregisters and thus causes her notes to be forwarded to her new GP. She may not get round to re-registering until she develops pelvic symptoms!

If the brown envelope has gone, and the woman did not leave enough of a forwarding address with her old GP to indicate which will be her new FPC, to what extent are we morally obliged to turn detective? Is the moral imperative to inform her of her need for treatment stronger than her right to confidentiality if it proves difficult to persuade remaining relatives or friends to supply her new address? If she has gone abroad, then there is no hope that the NHS Central Register will eventually be able to find her, so we must rely on social contacts. Oddly, this seems even to apply to servicewomen, and the families of servicemen, who have been posted abroad as certainly the RAF will not routinely forward NHS results.

It is our feeling that the fact that these abnormalities have been found as a result of a health-service-instigated investigation (the call or recall of a routine screening service) rather than 